\title{
The analysis of prognostic factors affecting post-radiation acute reaction after conformal radiotherapy for non-small cell lung cancer
}

\author{
Michał Spych ${ }^{1,2}$, Leszek Gottwald³, Małgorzata Klonowicz², Michał Biegała4 ${ }^{4}$, Robert Bibik', Jacek Fijuth ${ }^{1,2}$
}

\begin{abstract}
${ }^{1}$ Radiotherapy Department, Chair of Oncology, Medical University of Lodz, Poland 2Teleradiotherapy Department, Regional Centre of Oncology, Copernicus Memorial Hospital, Lodz, Poland

${ }^{3}$ Palliative Care Unit, Chair of Oncology, Medical University of Lodz, Poland

${ }^{4}$ Medical Physics Department, Regional Centre of Oncology, Copernicus Memorial Hospital, Lodz, Poland
\end{abstract}

Submitted: 27 October 2008

Accepted: 10 September 2009

Arch Med Sci 2010; 6, 5: 756-763

DOI: 10.5114 /aoms.2010.17092

Copyright (c) 2010 Termedia \& Banach

\section{Abstract}

Introduction: The aim was to evaluate the risk of acute side effects in the lung after 3-dimensional conformal radiotherapy (3D-CRT) in patients treated for nonsmall cell lung cancer (NSCLC). An attempt was made to single out clinical factors and factors related to treatment technique which may induce acute postradiation pneumonitis.

Material and methods: The analysis concerned 34 consecutive patients who underwent radical radiation therapy for NSCLC. Intensity of early toxicity was evaluated using modified RTOG/EORTC toxicity score. The endpoint for this analysis was the occurrence of radiation pneumonitis of grade 2 or higher. Factors related to treatment techniques were included in the statistical analysis. Results: Fifty-three percent of patients included in the study suffered from acute post-radiation pneumonitis. The results of the study revealed the existence of lung tissue sensitivity to low doses of ionizing radiation. The multivariate analysis showed that total lung volume receiving a low dose of $10 \mathrm{~Gy}$ increased the risk of post-radiation pneumonitis $(p=0.01)$.

Conclusions: Acute post-radiation pneumonitis was a relevant clinical problem in patients who underwent radical radiotherapy for non-small cell lung cancer. The lung volume receiving a dose of $10 \mathrm{~Gy}$ was the most important dosimetric factor which influenced the post-radiation acute pneumonitis.

Key words: NSCLC, conformal radiotherapy, post-radiation pneumonitis.

\section{Introduction}

The goal of radiotherapy is to cure cancer locally without excessive toxicity. The optimal way to achieve this goal is to precisely deliver an irradiation dose to the target volume, and no or a minimal dose to the uninvolved normal tissues and structures (organs at risk). Numerous studies suggest that higher irradiation dose results in better disease-free survival. In many tumours, such as carcinoma of the uterine cervix, prostate, and lung cancer, higher local control is correlated with increased survival.

Complete surgical resection is the most effective initial treatment for patients with early stage non-small cell lung cancer (NSCLC). Local relapses

\author{
Corresponding author: \\ Michał Spych, MD, PhD \\ Radiotherapy Department \\ Chair of Oncology \\ Medical University of Lodz \\ Paderewskiego 4 \\ 93-509 Lodz, Poland \\ Phone: +48426895551 \\ Fax: +48426895552 \\ E-mail: spychmichal@o2.pl
}


in the tumour bed and regional lymph nodes or distant metastases are the mechanism of relapse after curative resection [1, 2]. Radiation therapy is the primary treatment for NSCLC, either as adjuvant treatment after surgery or as radical treatment in patients with locoregional advanced, inoperable tumour. It was reported that high radiation doses were correlated with improvement of local control [3-5]. Radiation-induced pulmonary injury is one of the most common and serious complications in patients who receive high-dose radiation therapy for non-small cell lung cancer. The use of threedimensional conformal radiotherapy allows for improved target volume coverage as well as better ability to spare normal lung tissue. Nevertheless, the percentage of patients who experience postradiation pneumonitis fluctuates between $6 \%$ and $49 \%$ [6-20]. Several clinical factors as well as specific dose-volume histogram (DVH) parameters have been reported as risk factors for radiotherapyrelated lung injury in NSCLC patients. Poor performance status, concurrent smoking, age, low haemoglobin concentration, concurrent chemotherapy, history of chronic obstructive pulmonary disease (COPD), and poor pulmonary function before radiotherapy have been reported as common clinical factors related to post-radiation lung injury [17, 21-24]. Many studies have reported that the percentage volume of lung receiving more than some defined threshold dose and mean lung dose (MLD) are predictive factors for post-radiation acute lung toxicity. Most reported results in the literature are inconsistent. In this study we tried to express our opinion in the discussion. We herein report our study results of radiation-induced lung toxicity in a group of 34 patients with NSCLC, treated using three-dimensional conformal techniques. The aim of this study was to evaluate the risk of acute side effects in the lung after 3D-CRT in patients treated for NSCLC. An attempt was made to single out clinical factors and factors related to treatment technique which may induce acute post-radiation pneumonitis.

\section{Material and methods}

From September 2004 to March 2006, 34 consecutive patients were enrolled in a prospective study to evaluate pulmonary toxicity following 3D-CRT. They were treated in the Radiotherapy Department, Chair of Oncology of Medical University of Lodz. There were 25 males and 9 females in this group. The male : female ratio was $2.7: 1$. Patient's age was in the range 48-81 years (mean 63.4 years; standard deviation [SD] 8.4; median 63.0 years; $95 \%$ confidence interval [95\% Cl] 60.7-66.0). The clinical stage evaluation, and qualification of patients for radiation therapy were established after conducting medical examination, chest $x$-ray film in antero-posterior and lateral projection, chest computed tomography study, abdominal ultrasonography and bronchoscopy. The tumour size (the largest diameter defined in millimetres, measured in the chest computed tomography study) was in the range 20-85 mm (mean $45.3 \pm 18 \mathrm{~mm}$; median $40.0 \mathrm{~mm}$; $95 \% \mathrm{Cl} 39.7-50.8)$. In most cases, patients who were qualified for radical radiotherapy were in clinical stage III: frequency of stage III a and IIIb was $41 \%$ and $29 \%$ respectively. Seven patients (5 in clinical stage II and 2 in clinical stage I lung cancer) were disqualified from surgery because of other coexisting medical contraindications. Three patients in the analysed group ( 1 in clinical stage II and 2 in clinical stage I) did not consent to surgery. Clinical stage distribution according to TNM classification is presented in Table I.

The haemoglobin concentration before treatment fluctuated between $10.3 \mathrm{~g} / \mathrm{dl}$ and $15.9 \mathrm{~g} / \mathrm{dl}$ (mean 13.3 ×1.51 g/dl; median $13.3 \mathrm{~g} / \mathrm{dl}$; 95\% Cl 12.513.7). In the analysed group, patients' performance status was evaluated using the Karnofsky Performance Scale (KPS). All patients were in very good or good general condition. There were 4 (12\%) patients with $100 \%$ KPS. Sixteen (47\%) and 14 (41\%) patients were classified respectively as $90 \%$ and 80\% KPS. Twenty-five (73.6\%) patients underwent chemotherapy with a platinum-based regimen before radiation therapy. Twenty-one (61.8\%) patients received cisplatin in a dose of $100 \mathrm{mg} / \mathrm{m}^{2}$ with etoposide $100-120 \mathrm{mg} / \mathrm{m}^{2}$ every 21 days. Four (11.8\%) patients received cisplatin in monotherapy. The number of chemotherapy courses ranged between 2 and 5 (median 3.8 courses). In every case the diagnosis of non-small cell lung cancer was confirmed in histopathology examination. In the analysed group squamous cell carcinoma was diagnosed in 21 (61.8\%) patients. Adenocarcinoma was recognized in 5 (14.7\%) patients. The same

Table I. Clinical stage according to TNM classification

\begin{tabular}{|lccccc|}
\hline T/N & N0 & N1 & N2 & N3 & $\begin{array}{c}\text { No. of } \\
\text { patients }\end{array}$ \\
\hline T1 & 0 & 1 & 2 & 0 & 3 \\
\cline { 2 - 6 } & $0.00 \%$ & $2.94 \%$ & $5.88 \%$ & $0.00 \%$ & $8.82 \%$ \\
\hline T2 & 4 & 4 & 6 & 1 & 15 \\
\cline { 2 - 6 } & $11.76 \%$ & $11.76 \%$ & $17.65 \%$ & $2.94 \%$ & $44.12 \%$ \\
\hline T3 & 1 & 0 & 6 & 0 & 7 \\
\hline & $2.94 \%$ & $0.00 \%$ & $17.65 \%$ & $0.00 \%$ & $20.59 \%$ \\
\hline N4 & 2 & 2 & 3 & 2 & 9 \\
\hline $\begin{array}{l}\text { No. of } \\
\text { patients }\end{array}$ & 7 & 7 & 17 & 3 & 34 \\
\hline
\end{tabular}


number of patients had diagnosis of large cell carcinoma. In the remaining $3(8.8 \%)$ patients the precise pathological diagnosis was not established. In these cases non-small cell lung cancer was recognized.

\section{Treatment technique}

All patients were treated according to the Radiotherapy Department's homogeneous in-house protocol. Patients were positioned and fixed using a breast board with arms abducted over the head. Preliminary treatment volume localization was done using a simulator. The planning CT scans were sent to the Medical Physics Department, where treatment volumes as well as critical organs and radiation dose were defined using the Varian Eclipse treatment planning system. Every case was planned individually using three-dimensional conformal technique. Treatment volumes were defined according to the 50 and 62 ICRU (the International Commission on Radiation Units and Measurements) reports. The gross tumour volume (GTV) was delineated as the tumour with enlarged mediastinal lymph nodes (lymph nodes larger than $1 \mathrm{~cm}$ in computed tomography study). Next the clinical target volume (CTV) was defined as a volume which included the GTV and some subclinical disease. The CTV was usually created by adding a symmetrical margin of $5 \mathrm{~mm}$ to the GTV. Then an additional tissue margin around the CTV was created to eliminate the respiratory motion effect and potential inaccuracy of patient and radiation source setup. By adding these margins the planning target volume (PTV) was created. Margins around the CTV, in the range $1.0-1.5 \mathrm{~cm}$, usually were asymmetrical, and were dependent on respiratory motion and tumour site. Correctness of treatment plan realization was checked on a simulator, where treatment fields were transmitted to the patient's skin, and served in the computer system simultaneously. Treatment fields setup repeatability was evaluated through the simulator and accelerator image fusion and geometric error measurement. Twenty-one (64.8\%) patients had ipsilateral mediastinal lymph nodes irradiated electively. For precise delineation of individual mediastinal lymph node groups, Mountain and Dresler's classification modified by Chapet was used. The radiation dose in the elective volume was prescribed at a level of 50.0 Gy. Next the dose was escalated to the tumour and enlarged mediastinal lymph nodes, and it was contained within 66.0-68 Gy. For 11 (32.3\%) patients the "large field" technique was used, which included tumour and ipsilateral mediastinal lymph nodes. The total dose between 66.0 Gy and 68.0 Gy was prescribed in this group of patients. One patient was treated using the "small field" technique, limited to the tumour volume and pulmonary hilum lymph nodes. The prescribed dose was 66.0 Gy for this patient. All patients were irradiated using a conventional dosage schedule.

The basis of statistical analysis was occurrence of acute post-radiation pneumonitis in this group of patients. Intensity of early toxicity was evaluated once a week during radiotherapy, and then every 4 weeks, for six months after the end of treatment. A modified RTOG/EORTC toxicity score was used. The toxicity score modification involved changing the corticosteroid administration from grade 3 to grade 2 on the above-mentioned scale. The introduced change allowed us to single out a group of patients with indirect degree of post-radiation acute reaction course. Corticosteroid administration induced relatively rapid amelioration of respiratory system functioning in this group of patients, without the necessity of hospitalization. In the presented statistical analysis the main endpoint was the occurrence of radiation pneumonitis of grade 2 or higher according to the modified RTOG/EORTC toxicity score, with clinical manifestation of moderate effort dyspnoea with non-productive persistent cough, subfebrile body temperature and necessity of corticosteroid administration. In case of any uncertainty of pathogenesis of a patient's ailments, which could suggest local recurrence or tumour progression, computed tomography of the chest was performed as well as cardiological consultation to eliminate other causes of respiratory failure.

\section{Statistical analysis}

The Kaplan-Meier estimator was used to evaluate the risk of radiation pneumonitis development in the analysed patient group. Student's t-test, as a statistical method, was used to define differences between mean values of target volumes, mean doses cumulated in lung tissue as well as lung volumes receiving specified ionizing radiation doses, in groups of patients with and without clinical manifestation of post-radiation pneumonitis. Patient-related factors included in the analysis were: age, sex, tumour size, clinical stage, Karnofsky Performance Status, use of induction chemotherapy, and haemoglobin concentration before radiotherapy. Factors related to treatment techniques included in the analysis were: clinical target volumes and planning target volumes in $\mathrm{cm}^{3}$, volumes of lung tissue which received a dose from 10 Gy to 60 Gy, and mean lung doses. Finally, univariate and multivariate analysis was carried out, to single out factors which could describe the toxicity risk most precisely. Lung tissue, as an organ at risk, was defined separately in every case as: the ipsilateral lung, contralateral lung, and total lung volume. A $p$ value $<0.05$ was considered significant. 


\section{Results}

Fifty-three percent of patients included in the study suffered from acute post-radiation pneumonitis. Fifteen (44.1\%) patients experienced grade 2 , and 3 (8.9\%) patients grade 3 toxicity according to the modified RTOG/EORTC scale. No grade 4 toxicity was recorded in this study. All patients with grade 3 lung toxicity required hospitalization and intensive medical care. The mean time to clinical manifestation of acute postradiation reaction in patients who experienced postradiation pneumonitis was 5.3 weeks ( $\min 2.7$ weeks; max 16 weeks, median 7.4; 95\% Cl 4.2-8.7 weeks). In all patients except 2, acute post-radiation pneumonitis revealed itself before the end of the third month after the end of radiotherapy. In these 2 patients the acute post-radiation pneumonitis occurred at weeks 13 and 16 after the end of treatment.

The mean volumes of lung tissue which received doses in the range of 10-60 Gy in the analysed group are presented in Figure 1. A-C.

Clinical factors including age, sex, tumour size, clinical stage, Karnofsky Performance Status, use of induction chemotherapy, and haemoglobin concentration before radiotherapy did not have any impact on acute lung toxicity risk $(p \geq 0.18)$.

The analysis of dose-volume histograms showed a difference in lung volumes receiving low doses (10 Gy, $20 \mathrm{~Gy}$ ) in groups of patients with and without clinical manifestation of the side effect ( $p \leq 0.01$ ). The mean ipsilateral lung volume receiving $10 \mathrm{~Gy}$ in patients with post-radiation pneumonitis was $70.37 \%$, and only $57.22 \%$ in patients without clinical manifestation of this acute side effect $(p=0.002)$. Also differences of mean contralateral and total lung volume, in both groups of patients, with and without clinical manifestation of post-radiation pneumonitis, were statistically significant, at a dose level of 10 Gy. These differences were $46.04 \%$ vs. $31.44 \%$ for contralateral lung and $56.73 \%$ vs. $38.68 \%$ for total lung volume respectively ( $p=0.011 ; p<0.001)$. Statistically significant mean volume differences of ipsilateral lung tissue, contralateral and total lung volume were demonstrated for a 20 Gy dose as well. Differences in both groups of patients with and without clinical manifestation of post-radiation pneumonitis were $58.16 \%$ vs. $47.66 \%$ for ipsilateral lung $(p=0.007)$. For contralateral and total lung volume these differences were respectively $17.91 \%$ vs. $10.00 \%$ and $36.14 \%$ vs. $12.41 \%$ ( $p=0.016$; $p<0.001$ ). For lung tissue receiving higher doses, in the range of 30-60 Gy, statistically significant differences were observed in total lung volume only. For the dose of 30 Gy the difference was $25.23 \%$ vs. $14.59 \%$ ( $p<0.001$ ), and $19.28 \%$ vs. $11.36 \%$ for the dose level of 40 Gy $(p<0.001)$. For the 50 Gy and
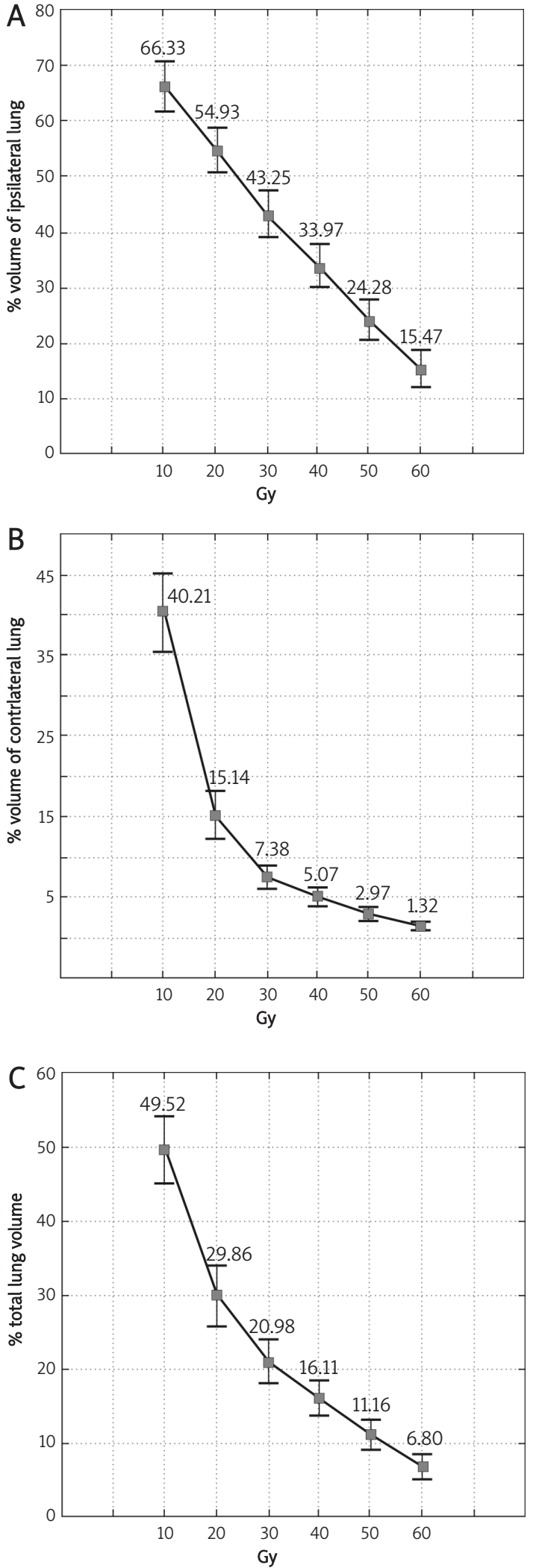

- Mean

I $\pm 0.95 \mathrm{Cl}$

Figure 1. The relationship between lung tissue mean volumes and absorbed doses in the range of 10-60 Gy. A-ipsilateral lung; B - contralateral lung; C-total lung volume 
60 Gy doses these differences, in mean total lung volumes, were respectively $13.51 \%$ vs. $7.64 \%$ and $8.64 \%$ vs. $4.02 \%$ in the groups of patients with and without clinical manifestation of post-radiation pneumonitis ( $p=0.001 ; p<0.003)$. Results of this analysis are presented in Table II. The analysis of the mean dose in the lung tissue defined as ipsilateral, contralateral and total lung volume showed a statistically significant difference in the case of total lung volume only. The mean dose which was absorbed in the total lung volume in the group of patients with post-radiation pneumonitis was $21.23 \mathrm{~Gy}$, compared with $15.86 \mathrm{~Gy}$ in the group of patients without any signs of this acute side effect $(p=0.008)$. Neither high dose volumes in the ipsilateral lung, contralateral lung, mean ipsilateral and contralateral lung doses, nor PTVs or CTVS $\left(\mathrm{cm}^{3}\right)$, showed a statistically significant difference in this patient population $(p \geq 0.07)$.

The univariate analysis showed that the lung volumes receiving a dose of $10 \mathrm{~Gy}$, ipsilateral lung and total lung volume receiving $20 \mathrm{~Gy}$, and total lung volume receiving doses of $30 \mathrm{~Gy}$ and $40 \mathrm{~Gy}$ were correlated with the post-radiation pneumonitis risk. The multivariate analysis showed that only total lung volume receiving a dose of $10 \mathrm{~Gy}$ was correlated with the risk of post-radiation pneumonitis $(p=0.01)$. Results of the univariate and multivariate analysis are presented in Tables III and IV.

\section{Discussion}

The clinical manifestation of acute post-radiation toxicity of the lung tissue is the most frequently occurring side effect in patients with NSCLC after radical radiotherapy, which limits the possibility to deliver a high dose of ionizing radiation. The use of 3D-CRT with a growing number of therapeutic beams orientated to the patient in varied angles and positions causes better ability to spare normal lung tissue, but a great deal of lung volume absorbs low, scattered doses. In the present study we have attempted to identify clinical and dosimetric factors which can be responsible for clinical manifestation of lung injury in patients after radical radiotherapy. In the evaluated patient group acute post-radiation pneumonitis grade 2 had clinical manifestation in 15 (44.1\%) patients, and 3 (8.9\%) patients experienced grade 3 toxicity on the modified RTOG/EORTC scale. No grade 4 was recorded. The occurrence of grade 2 toxicity in this group of patients was not a significant clinical problem. We observed relatively rapid respiratory function amelioration after corticosteroid administration in these cases. Multiple reports based on RTOG/EORTC toxicity scores have described the percentage of grade 2 in the range of $7.8-36 \%[6,10,14,15]$, and grade 3 in $2-14.3 \%$ of cases $[6,10,15]$. Inoue et al. reported toxicity of grade 1 and 2 in 36\% of patients. Grade 3 and 4 toxicity was reported in 13\%

Table II. Student's $t$ test results for mean volumes of lung tissue which received doses in the range of 10-60 Gy

\begin{tabular}{|c|c|c|c|c|c|}
\hline & Post RT (+) & Post RT (-) & $t$ & $\mathrm{df}$ & $p$ \\
\hline $\mathrm{V}_{10}$ ipsilateral lung & 70.37389 & 57.22625 & 3.447838 & 24 & 0.002 \\
\hline $\mathrm{V}_{10}$ contralateral lung & 46.04722 & 31.44583 & 3.636192 & 28 & 0.001 \\
\hline $\mathrm{V}_{10}$ total lung & 56.73556 & 38.68500 & 5.859693 & 28 & $<0,001$ \\
\hline $\mathrm{V}_{20}$ ipsilateral lung & 58.16222 & 47.66000 & 2.913252 & 24 & 0.007 \\
\hline $\mathrm{V}_{20}$ contralateral lung & 17.91167 & 10.99417 & 2.552560 & 28 & 0,016 \\
\hline $\mathrm{V}_{20}$ total lung & 36.14778 & 20.41667 & 5.410399 & 28 & $<0.001$ \\
\hline $\mathrm{V}_{30}$ ipsilateral lung & 45.67556 & 37.78500 & 1.870949 & 24 & 0.074 \\
\hline $\mathrm{V}_{30}$ contralateral lung & 7.86222 & 6.64583 & 0.852244 & 28 & 0.401 \\
\hline $\mathrm{V}_{30}$ total lung & 25.23111 & 14.59667 & 4.843179 & 28 & $<0.001$ \\
\hline $\mathrm{V}_{40}$ ipsilateral lung & 35.66556 & 30.15125 & 1.428069 & 24 & 0.166 \\
\hline $\mathrm{V}_{40}$ contralateral lung & 5.18278 & 4.90333 & 0.234055 & 28 & 0.816 \\
\hline $\mathrm{V}_{40}$ total lung & 19.28056 & 11.36417 & 4.204558 & 28 & $<0.001$ \\
\hline $\mathrm{V}_{50}$ ipsilateral lung & 25.66556 & 21.17125 & 1.206850 & 24 & 0.239 \\
\hline $\mathrm{V}_{50}$ contralateral lung & 2.96278 & 2.97333 & -0.013575 & 28 & 0.989 \\
\hline $\mathrm{V}_{50}$ total lung & 13.51056 & 7.64083 & 3.623866 & 28 & 0.001 \\
\hline $\mathrm{V}_{60}$ ipsilateral lung & 16.91389 & 12.22500 & 1.324020 & 24 & 0.198 \\
\hline $\mathrm{V}_{60}$ contralateral lung & 1.45611 & 1.11083 & 0.733943 & 28 & 0.469 \\
\hline $\mathrm{V}_{60}$ total lung & 8.64500 & 4.02000 & 3.276891 & 28 & $<0.003$ \\
\hline
\end{tabular}

Post RT (+) - patients with clinical manifestation of post-radiation pneumonitis, Post RT (-) - patients without any signs of side effects 
of patients in this study [6]. The group from St Louis described the risk of acute toxicity manifestation of grade 2 or higher in $14 \%$ of patients 6 months after radiotherapy. There were reported 4 deaths due to acute post-radiation pneumonitis [10]. Wang et al. reported the risk of acute lung toxicity of grade 3 or higher at a level of $6.7 \%$. About $4 \%$ of patients died because of this complication after radiotherapy in this study [14]. The group from the Memorial Sloan Kettering Cancer Centre reported $18.3 \%$ of patients with acute lung toxicity of grade 3 or higher according to the RTOG/EORTC toxicity score. The percentage of deaths due to lung toxicity was $4 \%$, similarly as in the Wang et al. study [15]. In our study the toxicity score modification consisted in changing the corticosteroid administration from grade 3 to grade 2 on the above-mentioned scale. The introduced change allowed us to single out a group of patients with indirect degree of postradiation acute reaction course. The lack of uniform criteria for post-radiation pulmonary injury makes it difficult to compare the incidence and severity of post-radiation pneumonitis between published data. In comparing published data it is important to take into account that therapeutic indications for corticosteroid administration may be different in particular centres and departments. The results of our study, if we refer to the percentage of patients with clinical manifestation of grade 3 acute postradiation pneumonitis according to RTOG/EORTC, are similar to published data from other centres $[6,10,15]$.

A number of recently published reports evaluating toxicity after radiotherapy in patients with NSCLC are based on detailed analysis of dose-volume histograms. The purpose of these studies was to detect factors that increased the risk of acute post-radiation pneumonitis. Investigators have demonstrated that the larger was the volume of lung tissue receiving some defined radiation dose, the higher was the risk of acute post-radiation lung injury. Some investigators have reported a similar relation to mean dose absorbed in the lung tissue. In the presented statistical analysis clinical manifestation of acute post-radiation pneumonitis revealed itself most often in patients who received low doses in a large volume of lung tissue, which was defined as ipsilateral, contralateral and total lung volume. The multivariate analysis conducted in the present study showed a strong relation between total lung volume receiving a dose of $10 \mathrm{~Gy}$ and the risk of acute lung injury. For lung volumes which received higher doses, in the range of 30-60 Gy, statistically significant differences were observed in total lung volume only.

Similar results were reported by Graham et al. In their study the dose of 20 Gy and the mean dose in total lung volume were the factors of the risk of
Table III. Univariate analysis results of prognostic factors related to treatment technique

\begin{tabular}{|c|c|c|c|}
\hline \multicolumn{3}{|c|}{ Factors related to treatment technique } & $P$ \\
\hline \multirow[t]{2}{*}{$\mathrm{V}_{10}$ ipsilateral lung } & $>63 \%$ & $50 \%$ & 0.005 \\
\hline & $<63 \%$ & $50 \%$ & \\
\hline \multirow[t]{2}{*}{$\mathrm{V}_{10}$ contralateral lung } & $>40 \%$ & $44 \%$ & 0.01 \\
\hline & $<40 \%$ & $56 \%$ & \\
\hline \multirow[t]{2}{*}{$\mathrm{V}_{10}$ total lung } & $>48 \%$ & $54 \%$ & $<0.001$ \\
\hline & $<48 \%$ & $46 \%$ & \\
\hline \multirow[t]{2}{*}{$V_{20}$ ipsilateral lung } & $>52 \%$ & $64 \%$ & 0.007 \\
\hline & $<52 \%$ & $36 \%$ & \\
\hline \multirow[t]{2}{*}{$\mathrm{V}_{20}$ contralateral lung } & $>15 \%$ & $49 \%$ & 0.090 \\
\hline & $<15 \%$ & $51 \%$ & \\
\hline \multirow[t]{2}{*}{$\mathrm{V}_{20}$ total lung } & $>28 \%$ & $56 \%$ & $<0.001$ \\
\hline & $<28 \%$ & $44 \%$ & \\
\hline \multirow[t]{2}{*}{$V_{30}$ ipsilateral lung } & $>39 \%$ & $73 \%$ & 0.057 \\
\hline & $<39 \%$ & $27 \%$ & \\
\hline \multirow[t]{2}{*}{$\mathrm{V}_{30}$ contralateral lung } & $>7 \%$ & $33 \%$ & 0.618 \\
\hline & $<7 \%$ & $67 \%$ & \\
\hline \multirow[t]{2}{*}{$\mathrm{V}_{30}$ total lung } & $>18 \%$ & $69 \%$ & $<0.002$ \\
\hline & $<18 \%$ & $31 \%$ & \\
\hline \multirow[t]{2}{*}{$\mathrm{V}_{40}$ ipsilateral lung } & $>30 \%$ & $61 \%$ & 0.229 \\
\hline & $<30 \%$ & $39 \%$ & \\
\hline \multirow[t]{2}{*}{$\mathrm{V}_{40}$ contralateral lung } & $>5 \%$ & $36 \%$ & 0.998 \\
\hline & $<5 \%$ & $64 \%$ & \\
\hline \multirow[t]{2}{*}{$\mathrm{V}_{40}$ total lung } & $>14 \%$ & $64 \%$ & 0.005 \\
\hline & $<14 \%$ & $36 \%$ & \\
\hline \multirow[t]{2}{*}{$\mathrm{V}_{50}$ ipsilateral lung } & $>21 \%$ & $64 \%$ & 0.148 \\
\hline & $<21 \%$ & $36 \%$ & \\
\hline \multirow[t]{2}{*}{$\mathrm{V}_{50}$ contralateral lung } & $>3 \%$ & $38 \%$ & 0.830 \\
\hline & $<3 \%$ & $62 \%$ & \\
\hline \multirow[t]{2}{*}{$\mathrm{V}_{50}$ total lung } & $>10 \%$ & $56 \%$ & 0.062 \\
\hline & $<10 \%$ & $44 \%$ & \\
\hline \multirow[t]{2}{*}{$\mathrm{V}_{60}$ ipsilateral lung } & $>13 \%$ & $45 \%$ & 0.169 \\
\hline & $<13 \%$ & $55 \%$ & \\
\hline \multirow[t]{2}{*}{$\mathrm{V}_{60}$ contralateral lung } & $>1.3 \%$ & $31 \%$ & 0.658 \\
\hline & $<1.3 \%$ & $69 \%$ & \\
\hline \multirow[t]{2}{*}{$\mathrm{V}_{60}$ total lung } & $>6 \%$ & $46 \%$ & 0.05 \\
\hline & $<6 \%$ & $54 \%$ & \\
\hline \multirow{2}{*}{$\begin{array}{l}\text { Mean dose } \\
\text { in ipsilateral lung }\end{array}$} & $>32 \mathrm{~Gy}$ & $61 \%$ & 0.061 \\
\hline & $<32 \mathrm{~Gy}$ & $39 \%$ & \\
\hline \multirow{2}{*}{$\begin{array}{l}\text { Mean dose } \\
\text { in contralateral lung }\end{array}$} & $>12 \mathrm{~Gy}$ & $46 \%$ & 0.220 \\
\hline & $<12 \mathrm{~Gy}$ & $54 \%$ & \\
\hline \multirow{2}{*}{$\begin{array}{l}\text { Mean dose } \\
\text { in total lung volume }\end{array}$} & $>18 \mathrm{~Gy}$ & $59 \%$ & 0.063 \\
\hline & $<18 \mathrm{~Gy}$ & $41 \%$ & \\
\hline
\end{tabular}


Table IV. Multivariate analysis results

\begin{tabular}{|lccccc|}
\hline & Beta & SD & HR & W & $p$ \\
\hline $\mathrm{V}_{10}$ ipsilateral lung & 0.16870 & 1.182774 & 1.183765 & 0.020344 & 0.887 \\
\hline $\mathrm{V}_{10}$ contralateral lung & 0.65372 & 0.654240 & 1.922673 & 0.998401 & 0.318 \\
\hline $\mathrm{V}_{10}$ total lung & -3.03132 & 1.208014 & 1.448252 & 6.296779 & 0.012 \\
\hline $\mathrm{V}_{20}$ ipsilateral lung & -0.97686 & 1.308891 & 0.376491 & 0.557003 & 0.455 \\
\hline $\mathrm{V}_{20}$ total lung & -0.02526 & 0.937207 & 0.975052 & 0.100727 & 0.978 \\
\hline $\mathrm{V}_{30}$ total lung & 1.01562 & 1.702373 & 2.761082 & 0.355923 & 0.551 \\
\hline $\mathrm{V}_{40}$ total lung & -0.68254 & 0.919531 & 0.505331 & 0.550967 & 0.458 \\
\hline
\end{tabular}

Beta-coefficient, SD - standard deviation, HR - hazard ratio, $W$ - Wald statistic

post-radiation lung toxicity. In univariate analysis the $p$ values for these variables were 0.001 and 0.01 respectively. The multivariate analysis demonstrated that the lung volume which received the low dose of 20 Gy was the only prognostic factor for evaluation of the risk of acute post-radiation pneumonitis $(p=0.001)$. Additionally, the authors reported a direct statistical correlation between lung volume which received a dose of 20 Gy and acute lung toxicity intensification. There were no reported cases of acute post-radiation pneumonitis in the group of patients which received a dose of $20 \mathrm{~Gy}$ in less than $22 \%$ of total lung volume. For the range $22-31 \%$ of total lung volume which received the above-specified dose, the authors reported acute post-radiation pneumonitis of grade 2 according to the RTOG/EORTC toxicity score in $8 \%$ of patients. In the group of patients which received a dose of 20 Gy in total lung volume larger than 40\%, the risk of serious incidents of acute post-radiation pneumonitis (grade 3-5 according to the RTOG/EORTC toxicity score) was $8 \%$. Three patients died due to acute lung toxicity in this group of patients [10]. Similar results were reported by a group from Mayo Clinic. The authors reported a statistically significant relation between clinical manifestation of grade 2 acute post-radiation pneumonitis and the mean dose in the total lung volume. A statistically significant relation between total lung volume which received a dose equal to or higher than 10,13, 15, 20 and $30 \mathrm{~Gy}$, and grade 2 lung toxicity was reported in this study as well [8]. The group from M.D. Anderson Cancer Centre confirmed a thesis on particular sensitivity of lung tissue to low total and fractional doses of ionizing radiation. The range of low radiation doses absorbed in a large volume of lung tissue in patients treated for NSCLC, as well as mean dose in lung tissue, had an impact on clinical manifestation of post-radiation pneumonitis. Patients who received a dose of 5 Gy in total lung volume smaller than $42 \%$ had a lower risk of postradiation lung toxicity compared to patients who received the same dose in a lung volume larger than $42 \%(p=0.001)$ [12].

In the present study a statistical correlation between percentage total lung volume which received higher doses (40, 50 and $60 \mathrm{~Gy}$ ) and the risk of clinical manifestation of post-radiation pneumonitis was demonstrated. This kind of correlation was not reported by authors from Washington University Medical Centre and Mayo Clinic [8]. This may result from differences in the definition of percentage total lung volume. The authors of those studies created total lung volume in the computer planning system excluding three volumes: GTV, CTV and PTV. In the present study ipsilateral and total lung volume were reduced by exclusion of CTV and PTV, but not GTV. Exclusion of these three volumes from the total lung volume could have a relatively large impact on the high dose distribution in lung tissue.

The presented results as well as published data indicate that the risk of lung toxicity clinical manifestation is the most important factor which limits our ability to safely deliver a planned dose of ionizing radiation inside the thorax. In the course of treatment planning it is very important to pay special attention to low dose distribution in lung volume. Such a disadvantageous low dose distribution in lung tissue may result from using a large number of oblique therapeutic beams, which permit the delivery of nearly $100 \%$ of the planned dose to the PTV, but on the other hand significant lung tissue volume absorbs a low, dispersed dose of ionizing radiation. New treatment techniques of radiotherapy in patients with NSCLC are being evaluated to spare lung tissue and other organs and to reduce the toxicity risk $[25,26]$. Additional studies are needed for a more robust description of the dose-volume effect following thoracic irradiation in lung cancer patients.

In conclusions, in this analysis, the lung volume receiving a dose of $10 \mathrm{~Gy}$ is the most important dosimetric factor which influenced the postradiation acute pneumonitis. Clinical manifestation of acute post-radiation pneumonitis revealed itself 
most often in patients who received low doses in a large volume of lung tissue.

\section{References}

1. Kepka L, Bujko K, Zolciak-Siwinska A. Risk of isolated nodal failure for non-small cell lung cancer (NCSLC) treated with the elective nodal irradiation (ENI) using (3D-CRT) techniques - a retrospective analysis. Acta Oncol 2008; 47: 95-103.

2. Sanuki-Fujimoto N, Sumi M, Ito $Y$, et al. Relation between elective nodal failure and irradiation volume in non-small cell lung cancer (NCSLC) treated with radiotherapy using conventional fields and doses. Radiother Oncol 2009; 91: 433-7.

3. Perez CA, Bauer M, Edelstein S, Gillespie BW, Birch R. Impact of tumor control on survival in carcinoma of the lung treated with irradiation. Int I Oncol Radiat Biol Phys 1986; 12: 539-47.

4. Hazuka MB, Turissi AT 3rd, Lutz ST, et al. Results of high dose thoracic irradiation incorporating beam's eye view display in non small cell lung cancer: a retrospective multivariete analysis. Int J Radiat Oncol Biol Phys 1993; 27: 273-84.

5. Hayman JA, Martel MK, Ten Haken RK, et al. Dose escalation in non small cell lung cancer using three dimensional conformal radiation therapy: update of a phase I trial. J Clin Oncol 2001; 19: 127-36.

6. Inoue A, Kunitoh H, Sekine I, Sumi M, Tokuuye K, Saijo N. Radiation pneumonitis in lung cancer patients: a retrospective study of risk factors and the long term prognosis. Int J Radiat Oncol Biol Phys 2001; 49: 649-55.

7. Yorke ED, Jackson A, Rosenzweig KE, Braban L, Leibel S, Ling C. Correlation of dosimetric factors and radiation pneumonitis for non small cell lung cancer patients in a recently completed dose escalation study. Int J Radiat Oncol Biol Phys 2005; 63: 672-82.

8. Schallenkamp JM, Miller RC, Brinkmann DH, Foote T, Garces $\mathrm{Y}$. Incidance of radiation pneumonitis after thoracic irradiation: dose volume correlates. Int J Radiat Oncol Biol Phys 2007; 67: 410-6.

9. Kong FM, Hayman JA, Griffith KA, et al. Final toxicity results of radiation-dose escalation study in patients with non small cell lung cancer (NSCLC): Predictors of radiation pneumonitis and fibrosis. Int I Radiat Oncol Biol Phys 2006; 65: 1075-86.

10. Graham MV, Purdy JA, Emami B, et al. Clinical dose-volume histogram analysis for pneumonitis after 3D treatment for non small cell lung cancer (NSCLC). Int J Radiat Oncol Biol Phys 1999; 45: 323-9.

11. Sunyach MP, Falchero L, Pommier P, et al Prospective evaluation of early lung toxicity following three dimensional conformal radiation therapy in non small cell lung cancer. Preliminary results. Int J Radiat Oncol Biol Phys 2000; 48: 459-63.

12. Wang $\mathrm{S}$, Liao Z, Wei $\mathrm{X}$, et al. Analysis of clinical and dosimetric factors associated with treatment - related pneumonitis (TRP) in patients with non small cell lung cancer (NSCLC) treated with concurrent chemotherapy and three dimensional conformal radiotherapy (3D-CRT). Int J Radiat Oncol Biol Phys 2006; 66: 1399-1407.

13. Fay M, Tan A, Fisher R, Mac Manus M, Wirth A, Ball D. Dose-volume histogram analysis as predictor of radiation pneumonitis in primary lung cancer patients treated with radiotherapy. Int J Radiat Oncol Biol Phys 2005; 61: 1355-63.

14. Wang JY, Chen KY, Wang JT, et al. Outcome and prognostic factors for patients with non small cell lung cancer and severe radiation pneumonitis. Int J Radiat Oncol Biol Phys 2002; 54: 735-41.

15. Yorke ED, Jackson A, Rosenzweig KE, et al. Dose - volume factors contributing to the incidence of radiation pneumonitis in non small cell lung cancer patients treated with three-dimensional conformal radiation therapy. Int J Radiat Oncol Biol Phys 2002; 54: 329-39.

16. Claude L, Perol D, Ginestet Ch, et al. A prospective study on radiation pneumonitis following conformal radiation therapy in non small cell lung cancer: clinical and dosimetric factors analysis. Radiother Oncol 2004; 71: 175-81.

17. Rancati T, Ceresoli GL, Gagliardi G, Schipani S, Cattaneo GM. Factors predicitng radiation pneumonitis in lung cancer patients: a retrospective study. Radiother Oncol 2003; 67: 275-83.

18. Willner J, Jost A, Baier K, Flentje M. A little to a lot or a lot to a little? Strahlenther Onkol 2003; 179: 548-56.

19. Hernando ML, Marks LB, Bentel GC, et al. Radiation induces pulmonary toxicity: a dose - volume histogram analysis in 201 patients with lung cancer. Int J Radiat Oncol Biol Phys 2001; 51: 650-9.

20. Hope AJ, Lindsay PE, Naqa IE, et al. Modeling radiation pneumonitis risk with clinical, dosimetric, and spatial parameters. Int J Radiat Oncol Biol Phys 2006; 65: 112-14.

21. Schild SE, Stella PJ, Geyer SM, et al. The outcome of combined modality therapy for stage III non small cell cancer in the elderly. J Clin Oncol 2003; 21: 3201-6.

22. Robnett TJ, Machtay M, Vines EF, McKenna MG, Algazyk KM, McKena WG. Factors predicting severe radiation pneumonitis in patients receiving definitive chemoradiation for lung cancer. Int J Radiat Oncol Biol Phys 2000; 48: 89-94.

23. Robert F, Childs HA, Spencer SA, Redden DT, Hawkins MM. Phase I/II study of concurrent paclitaxel and cisplatin with radiation therapy in locally advanced non small cell lung cancer. Analysis of early and late pulmonary morbidity. Semin Radiat Oncol 1999; 9: 136-47.

24. Langendijk H, Jong J, Wanders R, Lambin P, Slotman B. The importance of pre-treatment haemoglobine level in inoperable non small cell lung carcinoma with radical radiotherapy. Radiother Oncol 2003; 67: 321-5.

25. Panakis N, McNair HA, Christian JA, et al. Defining the margins in the radical radiotherapy of non-small cell lung cancer (NSCLC) with active breathing control (ABC) and the effect on physical lung parameters. Radiother Oncol 2008; 87: 65-72

26. Cattaneo GM, Dell'oca I, Broggi S, et al. Treatment planning comparison between conformal radiotherapy and helical tomotherapy in the case of locally advancedstage NSCLC. Radiother Oncol 2008; 88: 310-8. 